\title{
Pengembangan Sistem Brooder Berbahan Dasar Uap Bensin sebagai Upaya Menekan Biaya Operasional Budi Daya Ayam Broiler
}

\section{Development of Brooder Sistem Based on Gasoline Steam as an Effort to Lower Operational Costs of Broiler Chicken Raising}

\author{
Kurriawan Budi Pranata ${ }^{*}$, Tri Ida Wahyu Kustyorini ${ }^{2}$, Muhammad Priyono Tri Sulistyanto ${ }^{3}$, \\ Muhammad Ghufron ${ }^{4}$, Sholikhan', Djoko Adi Susilo ${ }^{5}$ \\ ${ }^{1}$ Program Studi Pendidikan Fisika, Fakultas Sains dan Teknologi, Universitas Kanjuruhan Malang, Jl. S. Supriadi No.48, \\ Bandungrejosari, Kecamatan Sukun, Kota Malang, Jawa Timur 65148. \\ 2 Program Studi Peternakan, Fakultas Peternakan, Universitas Kanjuruhan Malang, , Jl. S. Supriadi No.48, Bandungrejosari, \\ Kecamatan Sukun, Kota Malang, Jawa Timur 65148. \\ 3 Program Studi Teknik Informatika, Fakultas Sains dan Teknologi, Universitas Kanjuruhan Malang, , Jl. S. Supriadi No.48, \\ Bandungrejosari, Kecamatan Sukun, Kota Malang, Jawa Timur 65148. \\ ${ }^{4}$ Jurusan Fisika, Fakultas Matematika dan Ilmu Pengetahuan Alam, Universitas Brawijaya Malang, Jl. Veteran, \\ Ketawanggede, Kecamatan Lowokwaru, Kota Malang, Jawa Timur 65145. \\ 5 Program Studi Pendidikan Matematika, Fakultas Sains dan Teknologi, Universitas Kanjuruhan Malang, , Jl. S. Supriadi \\ No.48, Bandungrejosari, Kecamatan Sukun, Kota Malang, Jawa Timur 65148. \\ *Penulis Korespondensi: kurriawan@unikama.ac.id \\ Diterima Oktober 2020/Disetujui juni 2021
}

\begin{abstract}
ABSTRAK
Ayam broiler merupakan komoditi ternak penghasil daging dalam rentang yang relatif singkat, namun efisiensi waktu penghasil daging tersebut membutuhkan biaya operasional budi daya yang cukup besar dan menguras banyak energi panas berbahan dasar gas LPG saat diterapkan proses brooder DOC (Day Old Chick) anakan ayam broiler selama 15 hari. Pelaksanaan proses brooder membutuhkan 12 tabung $3 \mathrm{~kg}$ gas LPG/hari dengan kapasitas budi daya 3000 ekor DOC ayam broiler. Tingginya biaya operasional brooder ini seringkali berdampak pada penyusutan penghasilan ekonomi peternak karena selalu bergantung dengan peningkatan harga gas LPG. Tujuan dari kegiatan pengabdian masyarakat ini untuk mereduksi biaya operasional brooder DOC ayam broiler melalui upaya pengembangan dan implemetasi pemanas alternatif menggunakan vaporasi uap bensin. Solusi penyelesaian masalah ini adalah dengan enam tahapan kegiatan: 1) Identifikasi secara nyata proses brooder di lapangan; 2) Analisis faktor menggunakan tabel sebab akibat; 3) Perbaikan prosedur tata laksana brooder 4) Rancang bangun brooder alternative; 5) Uji operasi sistem brooder yang telah dibuat; dan 6) Analisis hasil uji dampak perubahan. Hasil analisis permasalahan membengkaknya biaya operasional brooder meliputi proses tirai brooder yang kurang rapat, intensitas nyala bara api, dan mahalnya harga tabung gas LPG. Prosedur baru yang diusulkan adalah perbaikan tirai kandang DOC, pegaturan intensitas nyala bara api pada kondisi siang dan malam, dan menghilangkan ketergantungan kebutuhan gas LPG. Prosedur yang diusulkan ini mampu mereduksi pembengkakan biaya operasional brooder hingga $50 \%$.
\end{abstract}

Kata kunci: ayam broiler, brooder, DOC, gas LPG.

\begin{abstract}
Broiler chicken is one of popular alternative source of protein for local people in Indonesia due to the low price and good quality meat. However, broiler breeders unable obtain enough income because face high operating costs due to the animal feed and high consumption of LPG gas in the Day Old Chick (DOC) brooder process. During 15 days brooder DOC process, at least $36 \mathrm{~kg}$ /day of LPG gas is consumed for 3000 chicks. Therefore, the purpose of this community service activity is to reduce brooder DOC operational costs for broilers through research, development and implement an alternative heaters using gasoline vapor vaporization. Community service activities are carried out with six stages of activity, namely 1 . Real identification of the brooder process in the field 2. Factor analysis using a causes and effects table 3. Improvement of brooder management procedures 4 . Conduct an alternative low cost brooder design 5 . Investigation of the fabricated brooder sistem and 6 . Analysis of the results of the change impact test. The results of the high operational cost DOC process investigation are tight less of the brooder DOC curtain cage, uncontrolled the intensity of the flames, and unfixed of LPG price. The new procedure proposed is fixing the brooder DOC curtain cage, new setting intensity of the flames in day and night, and using an alternative low cost brooder design to avoid unfixed LPG gas price. The proposed procedure is able to reduce brooder operational costs by up to $50 \%$.
\end{abstract}

Keywords: broiler chicken, brooder, DOC, LPG gas 


\section{PENDAHULUAN}

Liquefied Petroleum Gas (LPG) $3 \mathrm{~kg}$ merupakan migas yang diproduksi oleh Pertamina yang disubsidi agar konsumen minyak tanah dapat beralih ke LPG. Program konversi ini dikhususkan bagi masyarakat kelas menengah ke bawah untuk menggantikan kelangkaan minyak tanah sekaligus menekan pengeluaran rumah tangga (Eka et al. 2020). Kelangkaan LPG kerap terjadi diberbagai wilayah karena adanya disparitas harga yang cukup tinggi antara LPG 3 kg dengan $12 \mathrm{~kg}$. Hal tersebut memancing dilakukannya tindakan pengoplosan (over tabung), akibatnya tabung menjadi langka, adanya perbedaan HET (harga eceran tertinggi) di pangkalan sangat berpotensi larinya LPG dari suatu daerah ke daerah lain. Kelangkaan gas LPG bersubsidi ukuran $3 \mathrm{~kg}$ di banyak wilayah menunjukkan distribusi LPG tidak dilakukan dengan baik dengan tata niaga yang lemah (Lingkan et al. 2018). Dampak nyata dari kelangkaan gas LPG ini adalah para peternak budi daya ayam broiler tidak dapat melakukan budi daya karena pada masa brooding sangat membutuhkan gas LPG. Pada masa brooding day old chick (DOC) atau anakan ayam benar-benar diperhatikan mulai dari suhu kandang (brooder) (Fatmaningsih et al. 2016), ransum yang diberikan (Farida et al. 2017), serta obat-obatan atau vaksin yang diberikan untuk proses pencegahan dan penguatan sistem imun DOC. Dibalik kerja keras dan prestasi para peternak ayam broiler terdapat berbagai macam kendala di saat masa brooding DOC (Gunawan et al. 2015). Peternak membutuhkan biaya operasional cukup besar saat pemakaian gas LPG sebagai penghangat buatan pengganti indukan sampai anak ayam dapat menyesuaiakan sendiri dengan suhu lingkungan (Zumrotun 2012). Hal yang sama juga dialami pada mitra kelompok ternak ayam broiler yang diketuai oleh Bapak Paito di Dusun Sumbersari, Desa Kesiman, Kecamatan Trawas, Kabupaten Mojokerto, Provinsi Jawa Timur yang bermitra dengan perusahaan Barata Makmur Mojokerto yang memiliki profil seperti pada Tabel 1.

Uraian pada Tabel 1 poin 8 , disaat harga normal Bapak Paito sebagai ketua dan pemilik usaha mendapatkan keuntungan bersih \pm Rp. 400.000. Namun, seringkali peternak plasma mengalami kerugian besar saat harga pasar mengalami penurunan (Ipul 2019). Pada bulan Mei 2019 hingga satu bulan setelah hari raya Idul Fitri, harga ayam anjlok hingga Rp 7.000/kg (Budianto, 2019). Hal ini sungguh tidak terprediksi oleh Bapak Paito, biasanya pada bulan menjelang puasa dan satu bulan setelah Ramadhan harga ayam di pasar selalu melambung tinggi. Pada kondisi tersebut Bapak

Tabel 1 Profil lengkap mitra kelompok ternak Plasma ayam broiler

\begin{tabular}{|c|c|}
\hline Uraian Profil & Data \\
\hline Nama usaha & Kelompok ternak plasma ayam broiler \\
\hline Alamat & $\begin{array}{l}\text { Dusun Sumbersari, RT } 004 \text { RW } 001 \text { Desa Kesiman, Kecamatan Trawas, Kabupaten } \\
\text { Mojokerto. }\end{array}$ \\
\hline Nama pemilik & Bapak Paito \\
\hline Lama usaha & $\begin{array}{l}5 \text { tahun ( } 2 \text { tahun ternak mandiri mulai } 2014-2016,3 \text { tahun ternak sistem plasma } \\
\text { mulai } 2017 \text {-sekarang). }\end{array}$ \\
\hline $\begin{array}{l}\text { Jumlah } \\
\text { anggota/karyawan }\end{array}$ & $\begin{array}{l}5 \text { orang dengan jobdis pekerjaan ( } 2 \text { orang rutinitas bilas cusi dan ganti air minum } \\
\text { ayam, } 3 \text { orang rutinitas pemberian pakan ayam). }\end{array}$ \\
\hline Jumlah produksi ayam & Satu periode ternak (47 hari) Bapak Paito hanya mampu membudidayakan \\
\hline $\begin{array}{l}\text { broiler per satu periode } \\
\text { ternak }\end{array}$ & $\begin{array}{l}2.000-3.500 \text { ekor ayam broiler, padahal kapasitas kandang hingga mencapai } \\
5.000 \text { ekor. Tetapi jika menerapkan teknologi budi daya terkini, dipastikan jumlah } \\
\text { budi daya hingga maksimal mencapai } 5000 \text { ekor. }\end{array}$ \\
\hline $\begin{array}{l}\text { Rerata omset per satu } \\
\text { periode ternak }\end{array}$ & $\begin{array}{l}\text { Jika harga pasar ayam broiler stabil yang ditunjukkan Gambar } 4 \text {. Omzet LABA } \\
\text { Bapak Paito mencapai } \pm \text { Rp } 5.000 .000 / \text { satu kali periode ternak. Omzet ini belum } \\
\text { dikurangi biaya operasional budi daya meliputi (gaji tetap } 5 \text { karyawan Rp } \\
\text { 1.750.000,@ karyawan Rp } 350.000 \text {, biaya listrik } 40 \text { hari Rp } 100.000,90 \text { tabung } \\
\text { gas EPG Rp } 1.710 .000,50 \text { karung sekam Rp } 500.000,10 \mathrm{~kg} \text { kertas koran Rp. } \\
100.000 \text {, transportasi Rp } 300.000 \text { ) total biaya operasional budi daya Rp } \\
4.460 .000 \text {. }\end{array}$ \\
\hline $\begin{array}{l}\text { Rerata pendapatan per } \\
\text { satu periode ternak }\end{array}$ & $\begin{array}{l}\text { Terkadang rugi besar, jika beruntung harga pasar stabil rerata pendapatan bersih } \\
\pm \text { Rp } 400.000 \text { per satu periode ternak selama ( } 40 \text { hari budi daya }+7 \text { hari proses } \\
\text { pensterilan kandang meliputi pengerukan kotoran ayam pasca panen dan } \\
\text { penyiraman air disinfektan kandang menggunakan gayung air mandi). }\end{array}$ \\
\hline
\end{tabular}


Paito melakukan tindakan sigap melalui pemanenan ayam broiler secara dini meskipun pada malam hari seperti yang ditunjukkan pada Gambar 1.

Gambar 1a) menunjukkan kegiatan pemanenan ayam broiler secara sigap meskipun pada malam hari, Gambar 1b) Kegiatan pemanenan ayam broiler yang dilanjutkan pada pagi hari guna mengurangi kerugian biaya operasional karena harga pasar ayam broiler turun hingga batas ketidakwajaran. Turunnya harga ayam broiler mengakibatkan Bapak Paito terpaksa membiarkan kandangnya kosong selama dua bulan untuk meredam kerugian (Gambar 1c). Seperti yang ditunjukkan Tabel 1 point 7 , disebutkan biaya operasional budi daya yang paling besar adalah pemakaian gas LPG saat fase starter budi daya seperti yang ditunjukkan pada Gambar 2.

Gambar 2a menunjukkan andang milik Bapak Paito menggunakan brooder gas LPG dengan kebutuhan 12 tabung gas LPG/hari saat fase starter. Gambar 2b menunjukkan kebutuhan stok gas LPG wajib tersedia meskipun harganya semakin mahal dan langka. Mahalnya biaya operasional ini tidak sebanding dengan fluktuasi harga ayam di pasar seperti pada Gambar 2c, tampilan potret berita televisi dan berita media masa menyatakan pada bulan Juli 2019 harga ayam anjlok hingga Rp. 8000/kg. Hal ini berlanjut pada masa pandemi Covid-9 tahun 2020 harga ayam turun hingga mencapai Rp. 7000/kg. Sehingga, sebagian besar peternak ayam di Mojokerto tidak sanggup lagi untuk melakukan budi daya yang berujung pada kosongnya sementara kandang budi daya seperti yang ditunjukkan pada Gambar 2d.

Dampak dari turunnya harga ayam berimbas pada berkurangnya rasa percaya mitra industri terhadap peternak mitra plasma untuk melanjutkan keberlangsungan mitra kerja, tidak ada upah yang diterima peternak, dan berakibat pada kebangkrutan masal. Imbasnya banyak peternak menjadi pengangguran secara mendadak disertai menumpuknya hutang kebutuhan biaya operasional saat budi daya periode-periode sebelumnya. Masalah meredam biaya operasional budi daya dari kelompok peternak plasma ini merupakan masalah rutinitas yang tiada solusinya hingga saat ini. Seringkali para peternak mengeluh akan biaya operasional brooder fase starter pada saat perhitungan laba rugi hasil penjualan dengan pihak industri mitra kerja ternak. Setidaknya para peternak membutuhkan solusi teknis terkait inovasi brooder secara berkelanjutan dalam kurun waktu yang relative singkat.

Merujuk masalah utama di atas dari biaya operasional budi daya, yaitu terletak pada ke-

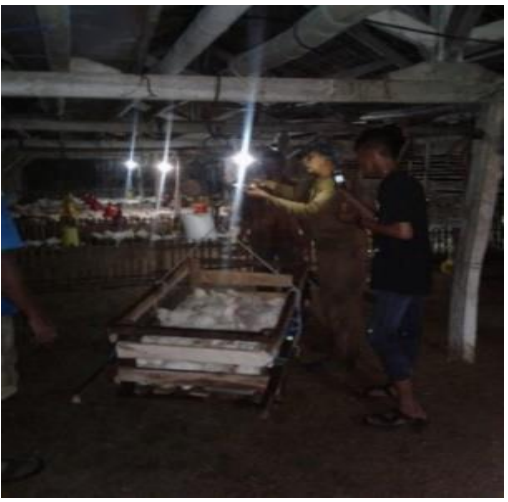

a

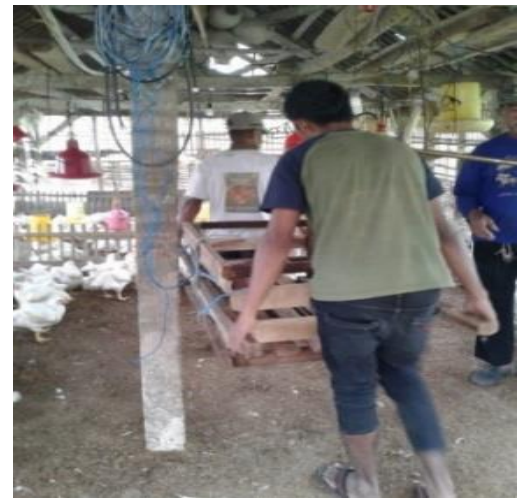

$\mathrm{b}$

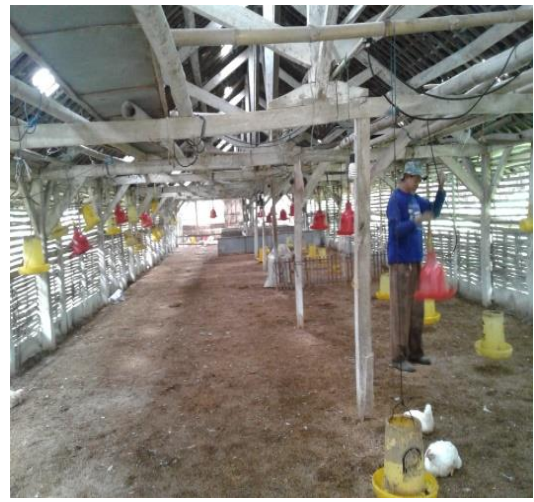

Gambar 1 a) Mitra melakukan pemanenan ayam broiler malam hari; b) Lanjut pagi hari; dan c) Kandang dibiarkan kosong.

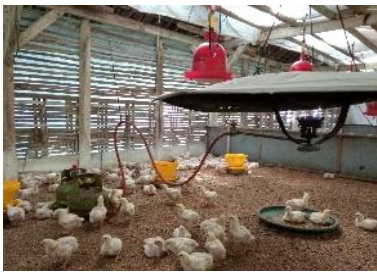

a

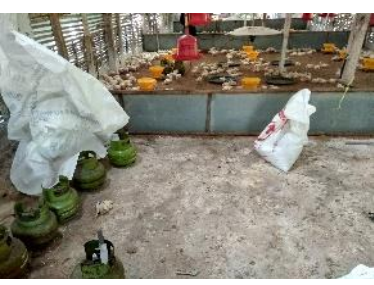

b

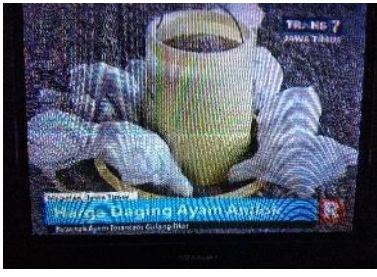

C

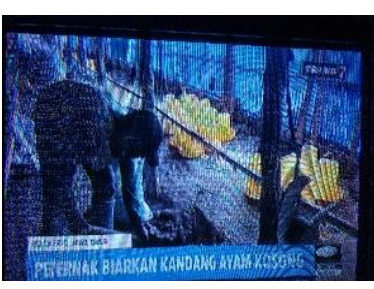

Gambar 2 a) Penghangat DOC berbahan dasar tabung gas LPG; b) Butuh banyak persediaan stok tabung gas LPG; c) Biaya operasional brooder tetap tinggi meskipun harga pasar daging ayam anjlok; dan d) Peternak wilayah Mojokerto membiarkan kandang ayam kosong. 
butuhan bahan bakar brooder akan membengkaknya biaya untuk LPG yang digunakan sebagai proses penghangat DOC pada fase starter. Ketergantungan pada LPG ini merupakan faktor yang sangat menghambat pertumbuhan modal usaha ternak ayam broiler baik mulai dari harga dan langkanya gas LPG. Hal ini perlu dilakukan rancangan teknis untuk memberikan solusi alternatif pemanas DOC yang hemat biaya, ketersediaan bakar melimpah, murah, dan terjangkau. Kegiatan pengabdian masyarakat ini telah merancang bangun pemanas alternatif yaitu menggunakan pemanas uap bensin yang termodifikasi hermetic compressor untuk menciptakan gelembung gas uap bensin menjadi suatu bahan bakar pemanas pengganti gas LPG. Tujuan dari kegiatan pengabdian masyarakat ini adalah untuk mereduksi biaya operasional brooder DOC ayam broiler melalui upaya pengembangan dan implemetasi pemanas alternatif menggunakan vaporasi uap bensin

\section{METODE PELAKSANAAN KEGIATAN}

\section{Lokasi dan Partisipasi}

Kegiatan pengabdian dilaksanakan selama empat bulan di Desa Kesiman, Kecamatan Trawas, Kabupaten Mojokerto pada kelompok peternak ayam broiler dengan ketua kelompok Bapak Paito dan juga sekaligus mitra tim pengabdi dari Universitas Kanjuruhan Malang. Pihak mitra sangat bereperan aktif dalam kegiatan pengabdian ini dalam hal penyediaan tempat pelatihan trial sistem alat, menyediakan tukang kuli batu, penyedian bahan baku saat keberlangsungan kegiatan pengabdian, serta partisipasi aktif dalam hal diskusi terkait keberlangsungan kegiatan.

\section{Alat dan Bahan}

Metode yang digunakan dalam pengembangan alat brooder alternatif ini melalui metode mekanisasi rancang bangun sistem brooder berbahan dasar uap bensin. Selama pandemi, pelaksanaan kegiatan pengabdian juga mengalami kendala karena keterbatasan tatap muka. Sehingga proses rancang bangun dimulai dari perakitan sistem broder dilakukan koordinasi secara jarak jauh mulai dari koordinasi pemesanan bahan baku hingga desain tata letak perakitan juga dikontrol oleh tim pengabdi agar sesuia desain yang dirancang oleh tim pengabdi. Jika bahan-bahan yang sekiranya sulit didapat dilokasi mitra, tim pengabdi memberikan alter- natif mencari bahan yang sulit didapat terebut dicari disekitar wilayah Kota Malang selanjutnya pengiriman barang tersebut kepada pihak mitra melalui jasa JNE seperti pengiriman sensor preasure gauge, saklar otomatisasi elektris tekanan udara preasure gauge, dan hermetic compressor. Saat dilakukan perakitan, tim pengabdi juga terlibat secara aktif melalui intruksi-intruksi melalui video call wa agar memudahkan pemahaman dan pembimbingan kepada tim mekanik dan mitra untuk menyelesaikan project yang dikerjakan. Setelah dari berbagai kendala proses perakitan, sesekali tim pengabdi mengunjungi tim mekanik untuk memonitoring dan mengevaluasi hasil kinerja tim mekanik agar sesuai dengan rancangan desain yang dibuat tim pengabdi. Perakitan sistem tandon gas uap bensin menggunakan dua tabung freon, satu tabung digunakan tendon bensin pertalit $1 \mathrm{~L}$ yang terhubung dengan hermetic compressor untuk menciptakan gelembung gas uap bensin. Hasil gelembung uap bensin kemudian dialirkan dan ditampung ke dalam tabung freon kedua yang dilengkapi dengan sistem monitoring tekanan gas menggunakan sensor preasure gauge untuk membaca seberapa besar tekanan gas yang berada di dalam tabung freon kedua. Sistem pada tabung freon kedua dilengkapi dengan saklar elektris preasure gauge sebagai sistem keselamatan kerja jika tekanan gas melebihi tekanan yang disetting pada tekanan tertentu. Pada sistem ini tekanan yang diatur pada tabung kedua sebesar 0,5-2,5 bar, jadi pada saat tekanan gas pada tabung freon kedua melebihi setting 2,5 bar secara otomatis hermetic compressor kondisi mati. Namun sebaliknya jika tekanan gas kurang dari 0,5 bar hermetic compressor kondisi menyala, begiru dan seterusnya sehingga terciptanya sistem brooder otomatisasi.

Hasil perakitan sistem broder yang dilakukan tim mekanik, selanjutnya dilakukan uji trial sistem untuk menguji hasil kinerja alat yang dibuat agar mengetahui kendala-kendala yang mungkin dievaluasi dan diperbaiki agar peforma sistem broder yang dibuat menjadi lebih baik. Hasil trial sistem telah ditunjukkan ada Gambar 3. Gambar 3a menunjukkan sistem broder menggunakan dua tabung yang satu sebagai pencipta gelembung uapa bensin dan yang kedua sebagai penerima uap gas. Keluaran uap gas bensin pada sistem tabung kedua dapat dilakukan selang percabangan untuk menimbulkan dua pamanas sekaligus. Gambar 3b menunjukkan nyala bara api yang relativ masih kecil pada uji coba trial 


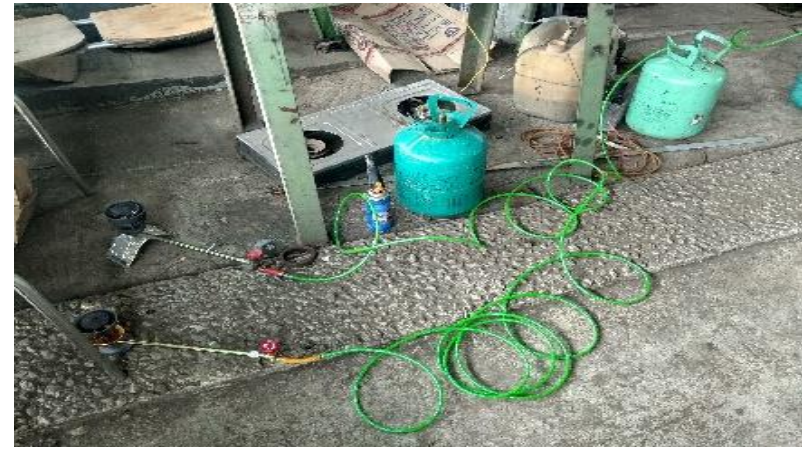

a

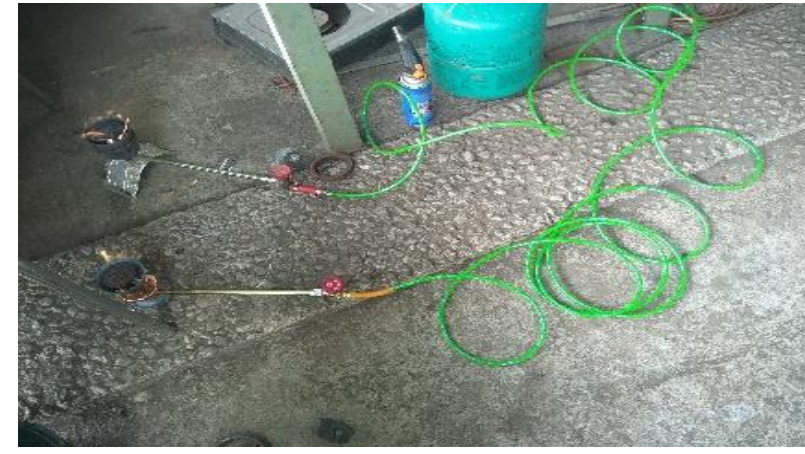

$\mathrm{b}$

Gambar 3 a) Sistem broder yang dibuat dapat diperlakukan percabangan dua pemanas bara api dan b) Nyala bara api masih kecil saat dilakukan trial.

pertama, artinya pada uji cobatrial ini masih diperlukan perbaikan dan evaluasi kesalahankesalahn yang terjadi dalam proses perakitan sistem.

Bahan yang digunakan dalam rancang bangun kegiatan pengabdian ini meliputi: tabung freon, hermetic compressor, selang udara, sensor preasure gage, electrode listrik, besi siku, kompor semawar buteerfly, naple gas, saklar listrik otomatis presuer gage, tabung dirigen, burner gas, master gas torch, filament payung aluminium penghantar panas, gasolec bertipe produk medion, kabel NYAF $2 \mathrm{~km}$, switching relay, dan MCB. Alat pendukung yang digunakan dalam rancang bangun kegiatan pengabdian ini meliputi: las listrik, gerindra, mesin bubut dan bor, multimeter digital, dan alat potong besi baja metabo metal cutting saw cpl CS23-355.

\section{Metode Pelaksanaan Kegiatan}

Prosedur kerja rancang bangun pemanas alternatif DOC memiliki 10 tahapan sebagai berikut: 1) Sosialisasi program disertai diskusi dengan mitra untuk menentukan rencana kerja berupa justifikasi kesesuaian spesifikasi teknis alat ayang akan dikembangkan; 2) Mengundang para ahli mekanisasi dan tukang bersama dengan mitra untuk menentukan komposisi alat dan bahan beserta perakitan sistem broder yang sesuai dengan keinginan mitra; 3) Perakitan sistem tandon penampung gas uap bensin serta instalasi perpipaan sistem drainase gas uap yang dikombinasikan dengan hermetic compressor; 4) Perakitan sistem elektrifikasi berupa sensor tekanan preasure gage yang termonitoring hingga 10 bar disertai juga saklar kontrol indikasi keamanan sistem jika tekanan yang dikontrol sesuai dengan kemanan sistem; 5) Uji coba trial sistem panas bara api yang dihasilkan oleh bahan bakar uap bensin serta uji ketahanan lama kinerja panas yang dihasilkan hingga orde 2, 4, 8, dan 10 jam pemakaian dengan kapasitas bahan bakar 1 L bensin pertalit; 6) Uji hasil gas buang yang dihasilkan dari sistem yang dikembangkan melalui metode uji organoleptic; 7) Setelah dilakukan berbagai uji trial sistem, dilakukan metode demplot dan pendampingan praktikum penggunaan kepada pihak mitra untuk mendeskripsikan setiap alur kerja sistem yang dibuat; 8) Melakukan uji kombinasi sistem broder yang dibuat dengan konduktor pemanas payung aluminium sebagai penghantar panas secara radiasi ke lingkungan udara, pada hari berikutnya juga melakukan uji kombinasi sistem broder yang dibuat dengan filament gasolec produk medioan sebagai pengantar panas media filament serat karbon untuk meradiasikan panas ke udara di lingkungan kendang; dan 10) Melakukan serah terima sistem broder, pada rentang satu bulan berikutnya dilakukan monitoring dan evaluasi sistem yang telah dibuat untuk menampilkan kelemahan-kelemahan sistem yang dibuat agar digunakan secara berkelanjutan.

\section{Bentuk Kegiatan}

Bentuk kegiatan yang diterapkan kepada mitra berupa sosialisasi, materi, demplot dan pendampingan praktikum berupa demonstrasi pengunaan sistem yang telah dibuat serta monitoring dan evaluaisi kinerja sistem yang telah dibuat selama proses penggunaan di lapangan.

\section{Metode Pengumpulan dan Analisis Data}

Metode pengumpulan data dengan wawancara kepada pihak mitra disertai pemberian angket observasi berisi tentang kegiatan setelah dilakukan penyampaian materi kegiatan pengabdian, testimoni cara penggunaan, kesukaran teknologi, dan kendala-kendala yang dihadapi mitra selama penggunaan sistem brooder al- 
ternatif yang dibuat. Sedangkan analisis data menggunakan metode deskriptif secra kualitataif berdasarakan hasil wawancara, angket, dan hasil ujian pre-test dan post-test yang dilakukan tim pengabdi.

\section{HASIL DAN PEMBAHASAN}

Secara garis besar hasil pelaksanaan kegiatan secara sistematis dan terstruktur yang terdiri dari 4 tahapan kerja yang meliputi: 1) Sosialisasi kegiatan beserta penentuan justifikasi tindakan rancang bangun sistem brooder dengan melibatkan mitra; 2) Perakitan dan ujicoba sistem 3) Demonstrasi dan demplot pendampingan; dan 4) Monitoring dan evaluasi program.

\section{Sosialisasi kegiatan beserta penentuan rancangan teknologi sistem brooder}

Sosialisasi program kegiatan pengabdian merupakan bentuk penyamaan persepsi yang dilakukan oleh tim pengabdi bersama mitra dengan tujuan untuk memyampaikan program yang diterapkam selama kegiatan PKM beserta alur dari jadwal kegiatan yang direncanakan agar kegiatan PKM yang diterapkan tetap mengacu kedisiplian time line yang telah ditentukan dan disepakati bersama. Tim pengabdi memberikan pengarahan kepada pihak mitra tentang pelaksanaan kegiatan pengabdian program kemitraan masyarakat (PKM) Dikti dan penyampaian tujuan dari kegiatan yang dilaksanakan. Hasil dari kegiatan tersebut, tim pengabdi mendorong komitmen pihak mitra untuk aktif berpartisipasi menyepakati jadwal pelaksanaan program PKM yang dicanagkan. Hasil kesepakatan komitmen tersebut, pihak mitra menyepakati jadwal hari pelaksanaan, pelibatan tim mekanik dan tukang kuli bangunan yang dilibatkan sesuai dengan arahan dari pihak mitra. Selain saling percaya antara tim pengabdi dan mitra, tim pengabdi juga melakukan seleksi wawancara kepada para mekanik dan kuli bangunan yang direkomendasikan oleh mitra guna mempertegas jadwal perakitan sistem menyamakan persepsi rancangan desain yang dibuat oleh tim pengabdi. Tim mekanik dan kuli bangunan sengaja dipasrahkan kepada pihak mitra karena kegiatan pengabdian ini dilakukan pada masa pandemi sehingga meminimalisasi mobilitas tim pengabdi juga merupakan hal penting disaat kegiatan pengabdian pada masa pendemi. Namun demikian, progres-progres hasil kerja tim mekanik senantiasa dimonitoring oleh tim pengabdi melalui video cal WA dengan melibatkan empat sumber daya manusia yang terdiri dari tim pengabdi, perwakilan mitra, tim mekanik, dan tukang kuli bangunan untuk memudahkan koordinasi perakitan rancangan sistem broder yang dikembangkan.

Rancangan teknologi sistem broder yang dikembangkan tim pengabdi telah dikoordinasikan dengan tim mekanik dan mitra untuk disepakati kesesuaian pemenuhan kebutuhan mitra. Rancangan yang dikembangkan ditunjukkan pada Gambar 4. Gambar 4 merupakan deskripsi gambaran sistem broder saat uji coba di lapangan yang ditunjukkan dalam bentuk gambar panah poin-poin sistem perbagian item unit yang dirancang. Penjelasan perbagian item unit telah dijelaskan dalam Tabel 2 .

Merujuk pada Tabel 2 item unit 1 merupakan hermetic compressor yang berfungsi menghisap udara lingkungan dan mengeluarkan udara bertekanan tinggi disalurkan ke item 2, yaitu ke tabung freon penampung bahan bakar bensin. Tabung freon item 2 ini menghasilkan gelembung gas uap bensin yang selanjutnya ditampung pada tabung freon item 3, yaitu penampung gelembung gas yang dilengkapi dengan sensor
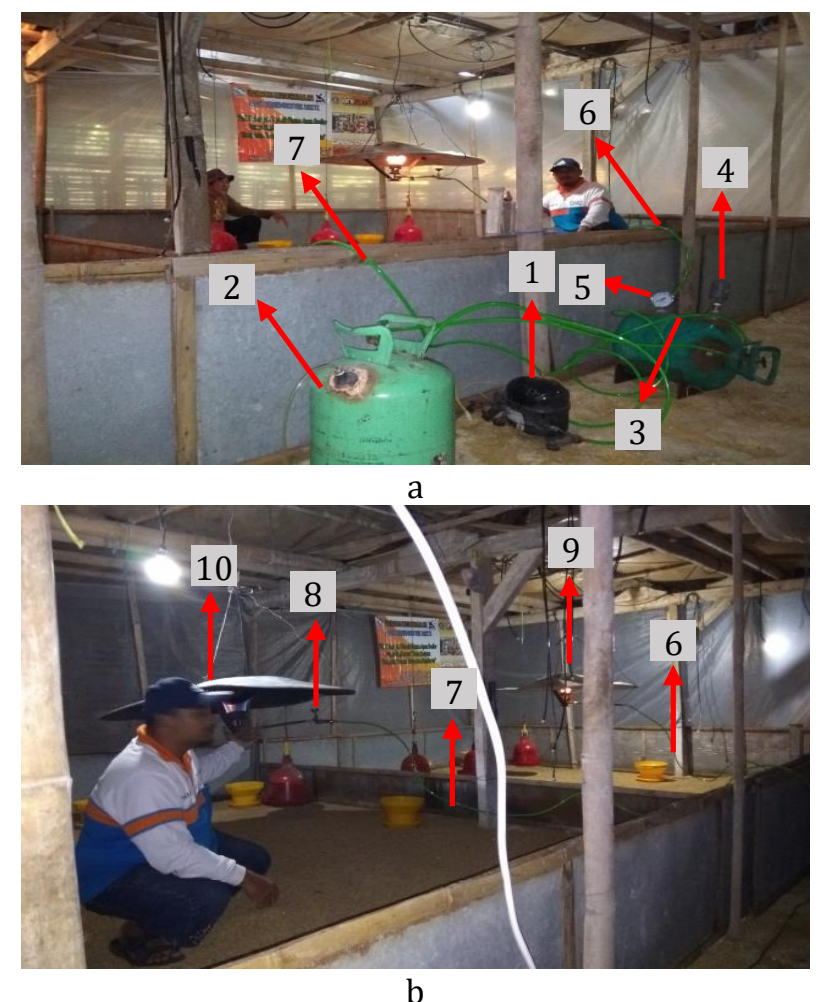

Gambar 4 a) Hasil rancangan sistem brooder berbahan dasar uap bensin (b) Hasil nyala bara api dari kedua pemanas secara bersamaan. 
preasure gauge (item 4) untuk membaca besarnya tekanan gas di dalam tabung freon item 3. Selain itu, tabung freon item 3 juga dilengkapi dengan saklar otomatis (item 5) untuk mengkontrol jumlah tekanan maksimum yang diterima oleh tabung freon item 3 sebagai safety agar tidak terjadi ledakan gas. Keluaran gas uap bensin yang berada pada tabung freon 3 disalurkan secara paralel menuju selang pemanas 1 (item 6) dan pemanas 2 (item 7). Pengaturan besar kecilnya keluaran gas pada tabung freon 3 diatur oleh valve pada kompor semawar butterfly yang terletak pada item 8. Sehingga satu unit sistem brooder uap bensin dengan kebutuhan $1 \mathrm{~L}$ bensin selama satu hari dapat menghasilkan dua nyala api seperti yang ditunjukkan pada item 9 dan 10.

\section{Hasil Uji Coba Sistem}

Hasil rancangan sistem brooder yang sudah dibuat selanjutnya dilakukan uji coba peforma kinerja nyala bara api yang dihasilkan terhadap lamanya waktu penggunaan pada orde $2,4,8$, dan 10 jam yang ditunjukkan pada Gambar 5. Gambar 5a menunjukkan nyala bara api 0-2 jam memiliki warna merah kehijau-hijauan yang dapat dipastikan warna tersebut merupakan pembawaan

Tabel 2 Deskripsi item unit rancangan sistem brooder berbahan dasar uap bensin

\begin{tabular}{cl}
\hline $\begin{array}{c}\text { No item } \\
\text { gambar } 6\end{array}$ & \multicolumn{1}{c}{ Deskripsi } \\
\hline 1 & $\begin{array}{l}\text { Hermetic Compressor } \\
\text { Tabung freon penampung bahan } \\
\text { bakar bensin } \\
\text { Tabung freon penampun gas uap } \\
\text { bensin }\end{array}$ \\
3 & Saklar listrik tekanan gas \\
5 & Sensor preasure gauge \\
6 & Selang keluaran pemanas 1 \\
7 & Selang keluaran pemanas 2 \\
8 & Valve kompor semawar butterfly \\
9 & Kondisi nyala api pemanas 1 \\
10 & Kondisi nyala api pemanas 2 \\
\hline
\end{tabular}

pewarna bensin pertalit yang juga berwarna hijau. Indikator warna hijau tersebut dapat diasumsikan uap gas bensin yang dibakar dalam rentang 0-2 jam masih memiliki kadar oktan yang tinggi. Hal ini juga diperkuat dari hasil pengamatan uji organoleptic menunjukkan keluaran gas buang pada rentang orde 0-2 menimbulkan bau yang menyengat tapi tidak menimbulkan polusi asap hitam pekat. Gambar 5b menunjukkan nyala bara api 2-4 jam warna hijau pada nyala bara api sudah mulai memudar dan lebih kuat menjadi warna api kuning seluruhnya. Pada rentang 2-4 jam hasil pengamatan uji organoleptic menunjukkan bau menyengat yang sudah mulai memudar dan tidak menimbulkan asap. Gambar 5c menunjukkan nyala bara api 4, 8, dan 10 jam nyala bara api sudah berubah warna menjadi nyala api biru seperti nyala api gas LPG. Pada rentang 4-10 jam ini bau menyengat yang ditimbulkan sudah mulai memudar dan tidak menimbulkan asap. Pada kondisi $\geq 10$ jam nyala bara api warna biru ini semakin mengecil, sehingga dapat dipastikan pada rentang di atas 10 jam peforma kinerja sistem brooder yang dibuat sudah tidak berfungsi secara optimal yang dipastikan kadar oktan energi pembakaran dengan kapasitas bensin 1 L sudah mulai habis dan dapat dipastikan sudah tidak dapat digunakan sebagai bahan bakar.

Pengembangan alat ini telah dikalkulasikan biaya operasional penggunaannya jika dibandingkan dengan penggunaan gas LPG. Selama ini perawatan DOC umur 1-15 hari membutuhkan biaya operasional yang mahal karena bergantung harga fluktuasi gas LPG yang sepenuhnya ditanggung oleh peternak plasma. Pemanas DOC dari umur 1-15 hari menggunakan gas LPG sebagai pengganti perawatan dari induk ayam yang sebenarnya. Kapasitas DOC 2.400 ekor membutuhkan 6 tabung gas LPG $3 \mathrm{~kg} / \mathrm{hari}$ dengan harga pertabung dipasaran Rp 19.000 (Effendy 2016). Sehingga, biaya selama rentang

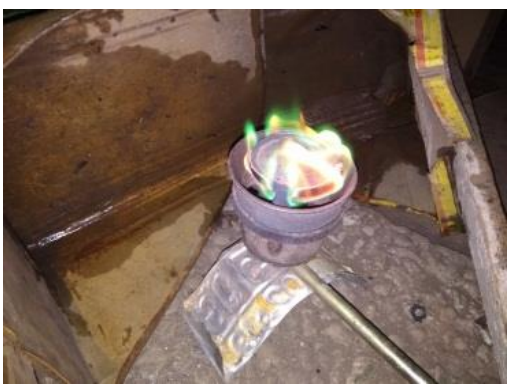

a

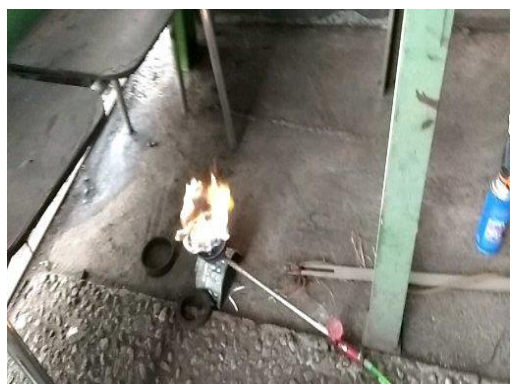

$\mathrm{b}$

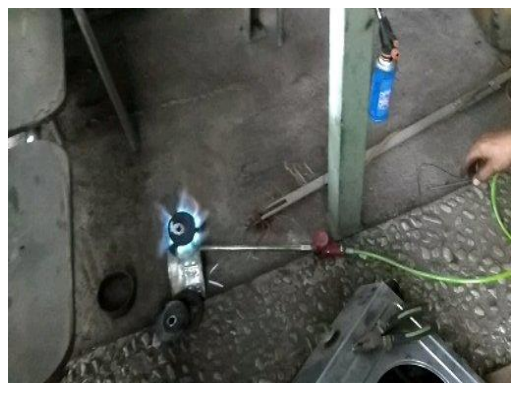

C

Gambar 5 a) Nyala bara api dari 0-2 jam; b) Nyala bara api 2-4 jam; dan c) Nyala bara api 4, 8, dan 10 jam. 
waktu 15 hari adalah 6 tabung x 15 hari x Rp. 19 . $000=$ Rp. 1.710.000. Oleh sebab itu, dibutuhkan solusi spesifik membuat brooder berbahan dasar bensin yang dimodifikasi hermetic compressor untuk menciptakan gelembung gas uap bensin yang ditampung dalam suatu tabung freon yang dilengkapi dengan otomatisasi sensor tekanan gas. Keluaran gas uap bensin dari tabung freon ini dikeluarkan melalui selang gas dan diteruskan hingga ke bagian ujung kompor semawar butterfly. Secara operasional dibutuhkan $1 \mathrm{~L}$ bensin seharga Rp 10.000 untuk dua pemanas brooder sehingga untuk menggantikan operasional budi daya yang membutuhkan 6 tabung gas LPG $3 \mathrm{~kg} /$ hari telah dibutuhkan $3 \mathrm{~L}$ bensin, maka biaya selama rentang waktu 15 hari adalah $3 \mathrm{~L}$ bensin $\mathrm{x} 15$ hari x Rp. $10.000=\mathrm{Rp} 450.000$. Dengan demikian peternak dapat menghemat biaya operasional sebesar Rp 1.260.000.

\section{Demonstrasi dan Demplot Pendampingan}

Setelah sistem dilakukan uji trial berulang kali dengan sinergitas mitra, tim mekanik dan tim pengabdi, telah ditemukan bebagai macam kendala yang selanjutnya dievaluasi dan diperbaiki secara bersama-sama hingga menghasilkan bara api yang cukup besar dan berwarna biru seperti yang ditunjukkan pada Gambar 6. Hasil kemapanan teknologi tepat guna yang diciptakan secara bersama tersebut kemudian dilakukan demonstrasi dan pendampingan secara real di dalam kondisi kandang yang sudah termodifikasi dengan konduktor pemanas payung aluminium yang berfungsi sebagai pemancar radiasi panas di dalam lingkungan kandang seperti yang ditunjukkan pada Gambar 6.

Hasil demplot pendampingan ini untuk meyakinkan dan menghilangkan rasa cemas mitra yang pada awalnya merasa cemas karena faktor estimasi ledakan dari uap gelembung gas bensin. Tim pengabdi melakukan demonstrasi secara terstruktur di hadapan pihak mitra pada kondisi setting sistem di lapangan disertai dengan penjelasan terperinci langkah-langkah kinerja yang harus dilakukan oleh mitra. Tim pengabdi juga menjelaskan bagian safety sistem yang harus dicermati yang meliputi: 1) Pemasangan posisi dan kondisi lajur penjalaran selang yang dilewati oleh gas uap bensin; 2) Tim pengabdi memperingatkan jangan sampai indikator baca sensor preasure gauge harus dipastikan berfungsi dan jangan sampai lebih dari 2,5 bar; dan 3) Sistem saklar otomatisasi juga harus dipastikan berfungsi karena saklar otomatisasi inilah yang menjadi kunci untuk mengkontrol besar perubahan tekanan di dalam tabung penampung gas uap bensin. Setelah berbagai penjelasan dan demplot pendampingan secara terstruktur yang dilakukan oleh tim pengabdi tersebut juga diyakinkan oleh tim pengabdi untuk mendampingi selama proses uji coba hingga rentang 5 jam dikandang mitra hingga malam hari mulai dari jam 14.30-19.30 WIB seperti yang ditunjukkan pada Gambar 6a. Uji coba dengan metode demonatrasi dan pendampingan kepada pihak mitra dilaksanakan secara langsung di dalam kandang untuk persiapan DOC yang dilakukan pada pukul 14.30 WIB. Selanjutnya, sistem tetap dibiarkan menyala hingga pada pukul 19.30 WIB kemudia tim pengabdi bersama mitra mengunjungi kandang pada kondisi malam hari untuk mengecek kestabilan dan ketahanan sistem jika dibiarkan hingga pada malam hari seperti yang ditunjukkan pada Gambar 6b dan menghasilkan kedua pemanas yang dibirakan menyala tersebut terlihat masih dalam kondisi stabil seperti yang ditunjukkan pada Gambar 6c.

\section{Monitoring dan Evaluasi Program.}

Dua minggu setelah dilanjutkan uji coba di lapangan dalam kandang dengan melibatkan pihak mitra, tim pengabdi melakukan monitoring dan evaluasi ke pihak mitra tentang sistem broder yang dibuat untuk mengetahui kendalakendala selama pemakaian seperti yang ditunjukkan pada Gambar 7. Hasil monev seperti yang

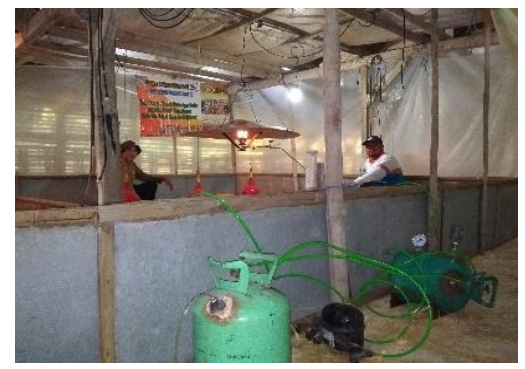

a

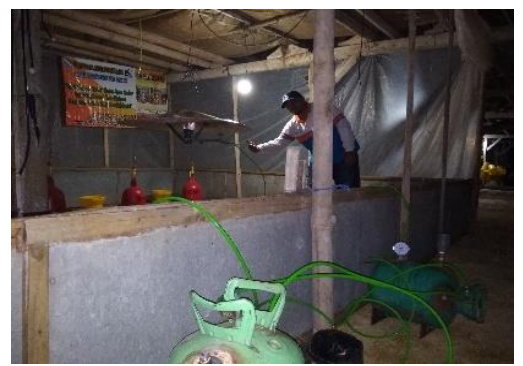

b

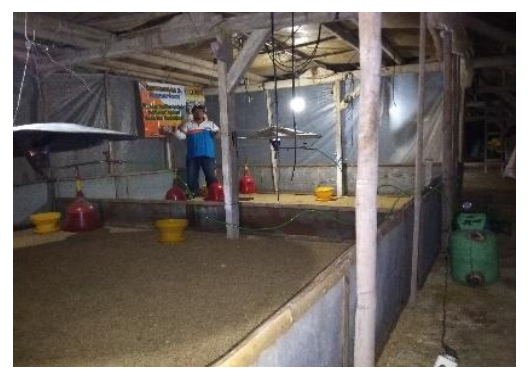

C

Gambar 6 a) Uji coba sistem didalam kondisi kandang pukul 14.30 WIB (b) Uji coba dilanjutkan sampai malam hingga pukul 19.30 WIB (c) Kedua pemanas dinyalakan secara bersamaan. 
dijelaskan pada Gambar 7, sistem brooder yang dikombinasikan dengan payung aluminium radiasi panas menunjukkan dua pancaran bara api dari kedua pemanas. Satu sistem broder uap bensin yang dibuat dapat dilakukan dua percabangan pemanas seperti yang ditunjukkan pada Gambar 9a pemanas pertama menghasilkan pancaran bara api berwarna biru yang mengindikasikan radiasi panas yang dihasilkan minim sekali polutan dan udara gas buang tidak berwarna hitam pekat. Namun, berbeda dengan pemanas bagian kedua seperti yang ditunjukkan pada Gambar 9b menunjukkan pancaran bara api berwarna merah dan kuning yang mengindikasikan pancaran api yang masih boros bahan bakar dan menimbulkan udara gas buang yang berwarna hitam pekat. Hasil kunjungan tim pengabdi ini selanjutnya dievaluasi untuk mencari penyelesaian dan kendala sistem yang telah digunakan oleh mitra selama dua minggu berjalan. Wawancara dilakukan sebanyak 5 responden untuk memperoleh data secara terstruktur kondisi di lapangan yang dialami oleh pihak mitra dengan memberikan berbagai pertanyaan sesuai dengan indikator pada Tabel 3.

Tabel 3 menunjukkan distribusi data dari penilaian kendala-kendala dan testimoni yang

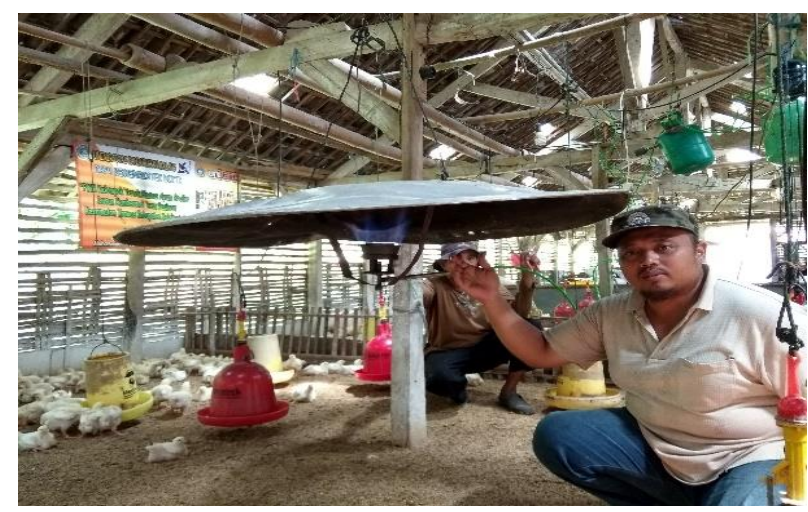

a dialami peternak saat menggunakan sistem broder uap bensin yang dikembangkan oleh tim pengabdi. Hasil wawancara tersebut beternak sangat bersemangat untuk mengembangkan sistem brooder yang dikembangkan oleh tim pengabdi sebagai broder alternatif untuk menekan biaya operasional budi daya fase starter.

\section{SIMPULAN}

Sistem brooder berbahan dasar uap bensin dapat menekan biaya operasional budidaya fase starter DOC yang awalnya membutuhkan gas LPG selama rentang waktu 15 hari yaitu 6 tabung $\times 15$ hari $\times$ Rp. $19.000=$ Rp. 1.710 .000 sekarang menjadi hemat jika menggunakan brooder uap bensin selama rentang waktu 15 hari yaitu 3 Liter bensin $\times 15$ hari $\times$ Rp. $10.000=$ Rp. 450.000 . Artinya peternak dapat menghemat biaya operasional budidaya sebesar $26,31 \%$. Peforma kinerja sistem brooder yang dirancang bangun dapat bekerja secara optimal hanya pada rentang waktu 10 jam untuk $1 \mathrm{~L}$ bensin pertalit. Hasil uji organoleptik pada rentang waktu 0-2 jam sistem brooder menimbulkan bau oktan bensin pertalit yang menyengat dengan indikasi nyala api

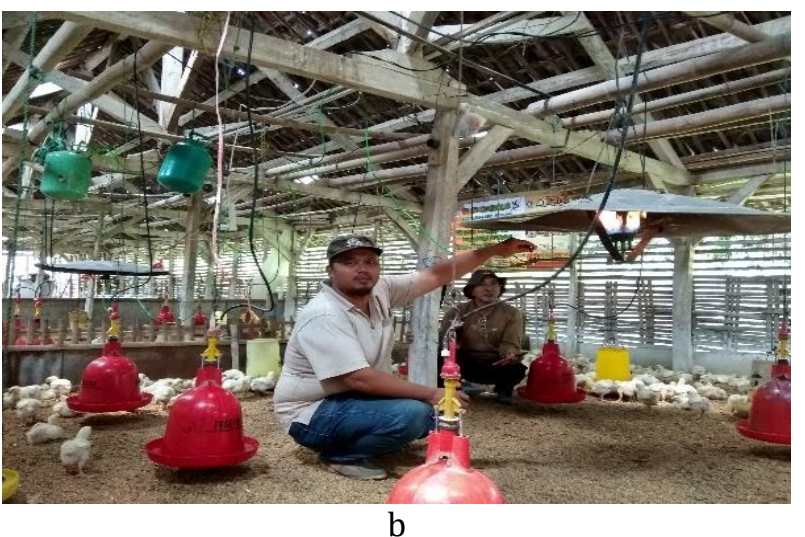

Gambar 7 a) Pemanas pertama dan b) Pemanas kedua.

Tabel 3 Hasil wawancara kuisioner monitoring dan evaluasi tim pengabdi kepada mitra meliputi indikator sebagai berikut

\begin{tabular}{lcc}
\hline \multicolumn{1}{c}{ Indikator penilaian } & Jumah & Presentase \\
& responden & $\%$ \\
\hline Apakah peternak mudah memahami materi yang disampaikan? & 3 & 60 \\
Apakah peternak paham prosedur kerja pengoperasian sistem broder? & 5 & 100 \\
Apakah peternak paham sistem safety dari broder yang dikembangkan tim & 4 & 80 \\
pengabdi? & 3 & 60 \\
Apakah peternak paham cara melakukan maintenece? & 3 & 60 \\
Apakah peternak paham cara melakukan penyimpanan? & 5 & 100 \\
Apakah peternak merasa terbantu dengan adanya sistem broder? & 5 & 100 \\
Apakah peternak berminat untuk mengembangkan sistem broder uap bensin? & 5 & \\
\hline
\end{tabular}


berwarna hijau. Sistem brooder uap bensin dapat menghasilkan nyala api berwarna biru seperti nyala api yang dihasilkan gas LPG pada rentang waktu 4-10 jam. Hasil uji pengamatan kondisi udara lingkungan sekitar sistem brooder uap bensin tidak menghasilkan polusi asap hitam. Hasil demplot pendampingan yang dilakukan oleh tim pengabdi peternak sudah tidak merasa cemas tentang estimasi kecurigaan ledakan gas uap bensin, karena sistem brooder yang dibuat telah dilengkapi dengan sistem safety yang termonitoring oleh sensor preasure gauge dan kontrol otomatisasi perubahan tekanan tabung penampung gas uap bensin. Hasil kombinasi sistem brooder dengan payung aluminium radiasi panas tidak mengurangi kualitas pancaran radiasi panas didalam kandang. Hasil wawancara monitoring dan evaluasi yang dilakukan tim pengabdi kepada mitra menunjukkan testimoni positif berupa peningkatan minat untuk mengembangkan sistem brooder uap bensin secara berkelanjutan.

Saran keberlanjutan dari kegiatan ini pentingnya dikembangkan lagi sistem brooder DOC yang lebih portable untuk diatur di dalam kandang peternak dengan menambahkan blower pemanas agar distribusi radiasi panas merata diseluruh titik posisi kandang dan juga pentingnya ditambahakan filterisasi gas buang hasil pembakaran uap bensin untuk mengurangi bau oktan bensin pertalit di dalam kandang dengan menambahkan sistem tungku Sanira melalui kombinasi sistem water sprayer.

\section{UCAPAN TERIMA KASIH}

Tim pengabdi mengucapkan terima kasih kepada Kementerian Riset, Teknologi, dan Pendidikan Tinggi (Ristekdikti) yang telah mem- berikan dana kegiatan pelaksanaan pengabdian masyrakat melalui skim hibah Program Kemitraan Masyarakat tahun pelaksanaan 2020.

\section{DAFTAR PUSTAKA}

Budianto EE. 2019. Peternak di Mojokerto Libur Sementara Pascaharga Ayam Anjlok, detikNews. [Internet]. [Diakses pada:]. Tersedia pada: https://news.detik.com/ berita-jawa-timur/d-4602083/peternak-dimojokerto-libur-sementara-pasca-hargaayam-anjlok.

Effendy SW. 2016. Analisis Tingkat Harga Yang Diterima Konsumen Gas LPG Ditinjau Dari Aspek Penawaran (Studi Kasus Kabupaten/Kota XYZ). JPFeb Unsoed. 6()., pp. 168-176.

Farida Y, SasongkoH, Sugiyarto, Budihardjo A. 2017. Granulasi dengan Matrix dari Residu Ekstraksi Kunyit sebagai Upaya Produksi Pakan Ayam Pedaging. Agrokreatif Jurnal Ilmiah Pengabdian kepada Masyarakat. 2(2): 87-91. agrokreatif.2.2.87-91

Fatmaningsih R, Riyanti R, Nova K. 2016. Performa Ayam Pedaging Pada Sistem Brooding Konvensional Dan Thermos. Jurnal Ilmiah Peternakan Terpadu. 4(3): 222-229.

Henry G, Baihaqi MI, Nurcahya O, Reindi RH, Rizki WZS. 2015. Pengaruh Manajemen Brooding Pada Pertumbuhan DOC (Broiler), Website. [Internet]. [Diakses pada: 10 Juni 2021]. Tersedia pada: https://karyadrh.blogspot. com/2015/11/pengaruh-manajemenbrooding-pada.html. 